\title{
RELAÇÃO ENTRE PESO DA CRIANÇA AO NASCER, ALTURA MATERNA, IDADE GESTACIONAL E RESTRIÇÃO ALIMENTAR EM GESTANTES NORMAIS
}

\author{
Cyro Ciari Junior*
}

Pedro Augusto Marcondes de Almeida*

Arnaldo Augusto Franco de Siqueira*

RSPU-B 245

CIARI Jr.. C. et al. - Relação entre peso da crança ao nascer, altura materna, ldade gestacional e restrição alimentar em gestantes normals. Rev. Saúde puibl., S. Paulo, 9:33-42, 1975.

Reslmo: For estudada a influência da altura materna, da idade gestacional $\epsilon$ da restriçäo almentar, em gestantes normais, sobre o peso da criança ao nascer. Verificou-se que o peso ao nascer aumenta com o aumento da altura materna e da idade gestacional. A restricão alimentar provocou uma diminuição de 251 gramas no yeso médıo do recém-nascido e foi responsável por um terço de todos os nascimentos de crianças de baixo peso. Os autores consideram que gestacões de 38 e 39 semanas, em mulheres de estatura inferior a $1.50 \mathrm{~m}$, podem acarretar um aumento do risco fetal. $A$ indicacão de dieta restritiva a gestante normal, pelo prejuizo que causa ao peso do recém-nascido, não deve basear-se apenas em esquemas rígidos de ganho de peso.

Unitermos: Recém-nascidos. peso; Gestantes, alimentação. Assistência pié-natal.

Vários estudos 7, 4. 12, 1: têm mostrado que a mortalidade neonatal em São Paulo é muito elevada 134 óbitos por mil nascidos rivos) quando comparada com a de países desenvolvidos ${ }^{*}$.

Há evidências, também, de que a qualidade da atenção pré-natal. ao parto e ao recém-nascido seja insatisfatória ${ }^{111}$ 1.2, 1.s.

Tem sido muito enfatizada, ultimamente. a relação entre baixo peso ao nascer e mortalidade neonatal le, por extensão. mortalidade infantili; Chase t. por exem- plo considera o peso ao nascer como a rariável de maior influência na mortalidade neonatal. A mesma autora exemplifica, dizendo que o simples fato de nos Estados L'nidos haver uma proporção de recémnascidos de baixo peso da ordem de $8 \% \mathrm{c}$ cotejados com $5 \%$ verificados na Holanda. explica $90 \%$ da diferença entre as respectivas mortalidades neonatais $120^{0}{ }_{00} \mathrm{n} . \mathrm{v}$. contra $13^{\text {o }}$ : n.v.) dos 2 países.

Percebe-se, assim, a importância enorme que o peso ao nascer exerce na sobrevivência dos recém-nascidos. Além disso.

Da Disciplina Higlene Materna do Departamento de Prática Médica em Saúde Pública da Faculdade de Saúde Pública da LSP - Av. Dr Arnaldo. 710 - São Paulo, SP — Brasil 
CIARI Jr., C et al. - Relação entre peso da criança ao nascer, altura materna, idade gestacional e restrição alimentar em gestantes normais. Rev. Saúde públ., S. Paulo, 9:33-42, 1975.

há muitas evidências ${ }^{15}$ de que também o desempenho. ou seja, a "performance" do indivíduo possa rir a ser irremediavelmente comprometida.

A proporção de recém-nascidos de baixo peso em São Paulo não é conhecida, mas foi estimada em cerca de 10'ć, valor muito elevado ${ }^{13}$.

Ltilizando o mesmo raciocínio feito por Chase ${ }^{1}$, pode-se dizer que a elevada proporção de recém-nascidos de baixo peso em São Paulo, ao lado das já citadas defíciências de atenção materno-infantil. concorre para a manutenção da elevada mortalidade neonatal.

Além da idade gestacional e da gemelaridade a altura materna e a desnutrição intra-uterina tem sido consideradas, mesmo em paises desenvolvidos ${ }^{11,15}$. contribuintes muito importantes para o baixo peso ao nascer.

Winick " calcula que nos Estados Lnidos. anualmente, 70.000 crianças nascem com peso inferior a 2.500 g. em virtude de desnutrição intrauterina. Essas crianças. segundo o mesmo autor, são as que estão sujeitas não só a falecer nos primeiros dias de vida, mas também a apresentar sérios problemas neurológicos e metaJólicos futuros.

Estimando-se para o município de São Paulo uma incidência de baixo peso ao nascer de $10 \%$. pode-se dizer, com base no número de nascidos viros $(150.000)$ que anualmente nascem cerca de 15.000 crianças de baixo peso, das quais 5.000 são prematuros verdadeiros e 10.000 são pequenas para a idade gestacional, ou seja, apresentam desnutrição intrauterina; dessas. 2.000 falecem no período neonatal, segundo levantamento de Siqueira ${ }^{1: 3}$ e um número talvez ainda maior no período pósneonatal. segundo Puffer e Serrano 1:. além dos problemas gerais de crescimento e desenvolvimento que os sobreviventes deverão apresentar.

Aceitando como verdadeira a hipótese de que a desnutrição materna seja a cau- sa de grande parte desse tipo de nascimento ${ }^{2,6,12}$, pode-se araliar a gravidade de que o problema se reveste. uma vez que o estado nutricional de uma boa proporção da população de gestantes no Brasil. especialmente na periferia das áreas metropolitanas, deve ser altamente insatisfatório.

Neste trahalho. estudou-se a relação entre idade gestacional e o peso ao nascer. a influência da altura materna e. mais especificamente. o efeito da restrição alimentar (em gestantes normais) sohre o peso do recém-nascido.

MATERIAL E MIETODOS

\section{Haterial}

Foram estudados os registros clínicos referentes a 403 gestações de mulheres normais matriculadas no Serviço de PréNatal do Centro de Saúde Geraldo de Paula Souza, selecionadas dentre todos os casos.

Os critérios de seleção foram os seguintes:

1. idade gestacional conhecida a partir da data da última menstruaçãol: 38 a 41 semanas;

2. medida da estatura da gestante:

3. existência de registros do peso da gestante em cada consulta de prénatal:

4. existência de dados sobre o recémnascido, numa consulta de retorno;

5. prescrição de restrição alimentar registrada na ficha.

\section{Método}

Para cada gestação incluída no estudo la unidade de trabalho foi a ge tação $e$ não a gestante, isto é. poderia haver mais 
CIARI Jr., C. et al. - Relação entre peso da criança ao nascer, altura materna, idade gestacional e restrição alimentar em gestantes normais. Rev. Saúde públ., S. Paulo, 9:33-42, 1975.

TABLA 1

Peso do recém-nascido relacionado à idade gestacional e altura materna

\begin{tabular}{|c|c|c|c|c|c|c|c|c|c|c|}
\hline \multirow[b]{2}{*}{$\begin{array}{l}\text { Alt. } \\
\text { Materna } \\
\text { (m) }\end{array}$} & \multicolumn{2}{|c|}{38 semanas } & \multicolumn{2}{|c|}{39 semanas } & \multicolumn{2}{|c|}{40 semanas } & \multicolumn{2}{|c|}{41 semanas } & \multicolumn{2}{|c|}{ Total } \\
\hline & $\begin{array}{c}\mathrm{No}^{\circ} \\
\text { casos }\end{array}$ & $\begin{array}{l}\text { Peso } \\
\text { (g) }\end{array}$ & $\begin{array}{c}N \cdot{ }^{\circ} \\
\text { casos }\end{array}$ & $\begin{array}{c}\text { Peso } \\
\text { (g) }\end{array}$ & $\begin{array}{c}\text { N.o } \\
\text { casos }\end{array}$ & $\begin{array}{c}\text { Peso } \\
\text { (g) }\end{array}$ & $\begin{array}{c}\text { N.o } \\
\text { casos }\end{array}$ & $\begin{array}{l}\text { Peso } \\
\text { (g) }\end{array}$ & $\begin{array}{c}\mathrm{N} .{ }^{\circ} \\
\text { casos }\end{array}$ & $\begin{array}{c}\text { Peso } \\
\text { (g) }\end{array}$ \\
\hline 1,49 e menos & 12 & 2911 & 12 & 2776 & 33 & 3218 & 1.3 & 3340 & 68 & 3099 \\
\hline 1,50 a 1,54 & 14 & 3090 & 32 & 3152 & 64 & 3301 & 23 & 3305 & 133 & 3244 \\
\hline 1,55 a 1,59 & 10 & 3073 & 23 & 3163 & 52 & 3360 & 12 & 3599 & 97 & 3313 \\
\hline 1,60 e mais & 15 & 2983 & 19 & 3128 & 46 & 3374 & 25 & 3464 & 105 & 3295 \\
\hline Total & 52 & 3011 & 86 & 3097 & 195 & 3320 & 70 & 3417 & 403 & 3249 \\
\hline
\end{tabular}

de uma gestação para uma mesma mulher), foram retirados da ficha de pré-natal os seguintes dados:

1. número da ficha;

2. altura da gestante;

3. todos os pesos da gestante, mês a mês;

4. data provável do parto;

5. data do parto;

6. peso ao nascer.

Foram ainda coletadas outras informações, como: sexo do nascituro, ordem de nascimento, aleitamento, peso da mulher na consulta de puerpério, dados esses que serão utilizados em outra oportunidade.

Os dados foram, a seguir, tabulados manualmente.

\section{RESULTADOS E DISCUSSAO}

A Tabela 1 mostra o peso médio ao nascer segundo a altura da mãe e a idade gestacional.

0 peso médio ao nascer foi de $3.249 \mathrm{~g}$. Considerando que esse peso refere-se apenas a gestações de termo (38 a 41 sema- nas) em mulheres normais, esse valor está bem abaixo do que se considera o melhor peso para o recém-nascido $(3.500$ a $4.000 \mathrm{~g}$ ).

Levando em conta o fato de a maioria das gestantes matriculadas no Serviço apresentar bom nível sócio-econômico ${ }^{1}$ e, por extensão, bom estado nutricional, procurouse encontrar uma explicação para o fato.

Sabe-se que há uma forte correlação entre altura materna e peso ao nascer ${ }^{3}$. Dessa forma, como $16,9 \%$ dos casos referiam-se a mulheres de estatura inferior a $1,50 \mathrm{~m}$ e $33,0 \%$ a mulheres de 1.50 a $1,54 \mathrm{~m}$, pode-se dizer que a baixa estatura de metade das mulheres matriculadas e incluídas no estudo explica em parte esse peso médio ao nascer insuficiente. No entanto, mesmo para os grupos de mulheres de maior estatura $(1,55$ a $1,59 \mathrm{~m}$ e $1,60 \mathrm{~m}$ e mais) o peso ao nascer, apesar de maior que nos outros grupos, também situou-se abaixo dos 3.500 g "ideais".

Ainda na Tabela 1 , ao analisar o peso ao nascer segundo a idade gestacional, verifica-se que, apesar de gestações de 38 e 39 semanas serem de termo, o peso médio do recém-nascido nessas idades foi bastante inferior ao verificado nas idades 40 e 41 semanas. 
CIARI Jr.. C. et al. - Relação entre peso da criança ao nascer, altura materna, idade gestacional e restrição alimentar em gestantes normais. Rev. Saúde pilbl., S. Paulo, 9:33-42, 1975.

Como $12,9 \%^{\circ}$ dos nascimentos rerificaram-se na $38 .^{\mathrm{a}}$ semana de gestação e $21.3 \%$ na $39 .^{a}$ semana. perfazendo $34.2 \%$ dos casos. não se pode negar a influência da idade gestacional no peso médio ao nascer rerificado neste trabalho.

Comprora-se. assim, a grande importância que o final da gestação. ou seja. as últimas 3 ou 4 semanas exercem sobre o peso do recém-nascido. como já tem sido descrito

Analisando em conjunto as duas variáveis, vê-se que os menores pesos médios ao nascer rerificaram-se nos grupos de 38 e 39 semanas, para mulheres de $1.49 \mathrm{~m}$ e menos.

Talvez a associação de gestações de 38 + 39 semanas. em gestantes de haixa estatura deva ser considerada como um fator de risco fetal.

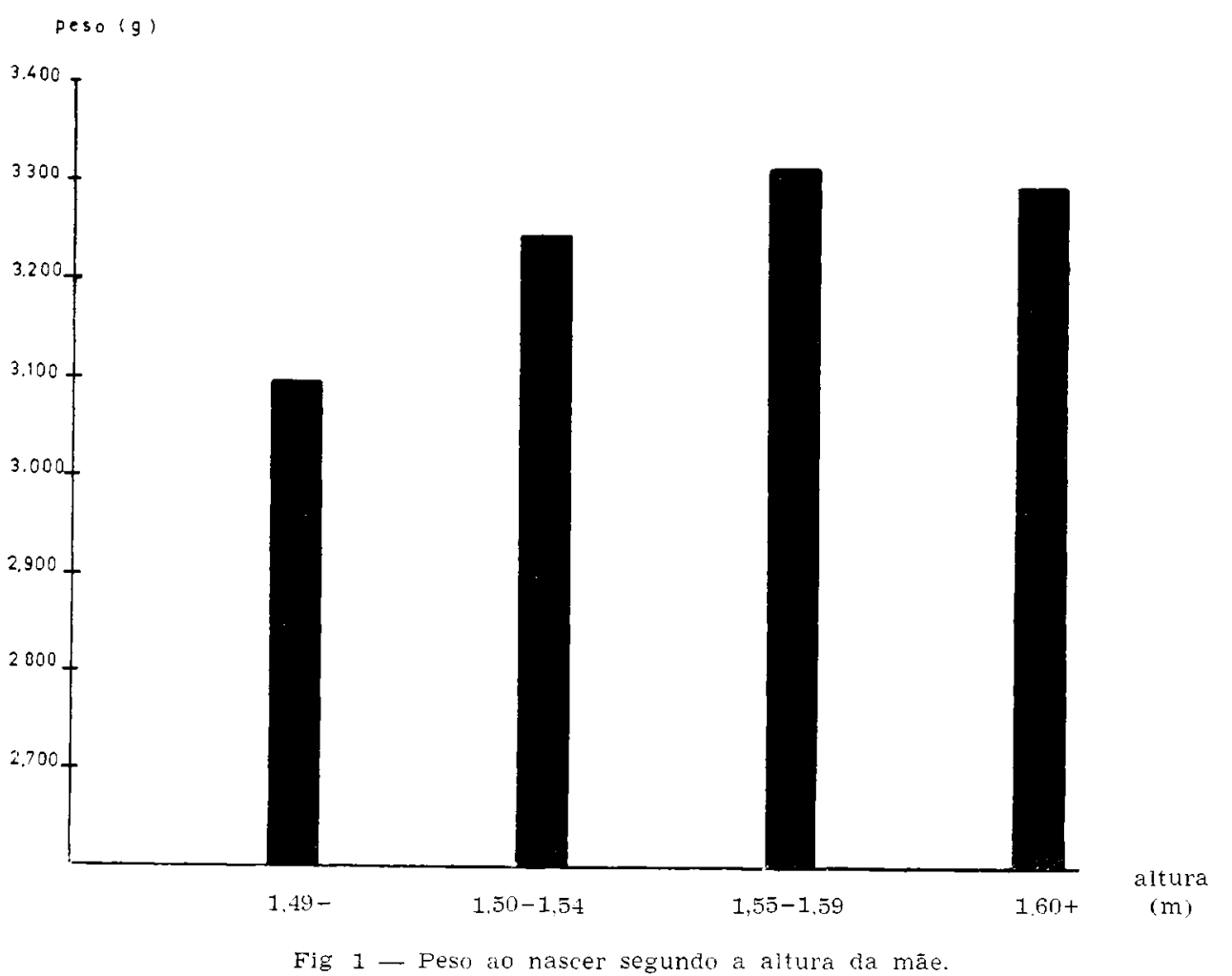

As Figuras 1 e 2 ilustram o fenômeno.

Quanto ao problema da restrição alimentar. o critério para a inclusão de uma gestação no grupo "com restrição alimentar" exigia pelo menos um ganho de peso mensal igual ou inferior a $500 \mathrm{~g}$. a partir do $3 .^{\circ}$ mês. ou quando houvesse prescrição de regime. Os casos em que houve a prescrição da dieta restritiva mas o ganho de peso da gestante continuou igual ou maior de um quilo por mês foram consdierados "sem restrição alimentar"

A necessidade da restriçāo alimentar (ou talvez. simplesmente de sódio) na gestação decorre do fato de ser o ganho "excessiro" de peso um pródromo da toxemia gravidica. mesmo quando ainda não se hipertensão. manifestaram o edema. a proteinúria ou a 
CIARI Jr., C. et al. - Relação entre peso da criança ao nascer. altura materna, idade gestacional e restrição almentar em gestantes normais. Rer. Salie puibl. S. Paulo, 9:33-42, 1975

$\operatorname{peso}(g)$

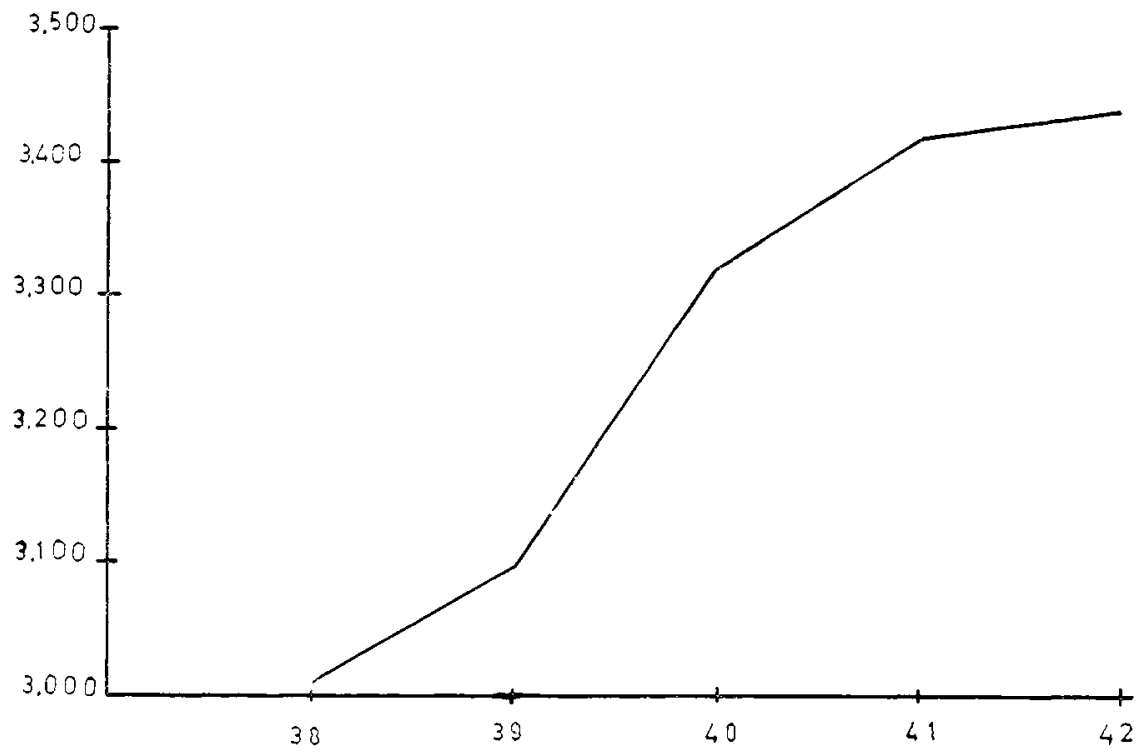

Fig. 2 - Peso ao nascer segundo a idade gestacional.

TA B LA 2

Peso médio ao nascel de filhos de mulheres normais, segundo a altura da mulher e a ocorrência de restrição alimentar (gestasões de 38 a 41 semanas)

\begin{tabular}{|c|c|c|c|c|}
\hline \multirow{2}{*}{ Altura materna $(\mathrm{m}$ ) } & \multicolumn{2}{|c|}{ Com restrição alimentar } & \multicolumn{2}{|c|}{ Sem restrigão alimentar } \\
\hline & No & $\begin{array}{l}\text { Peso médio } \\
(\mathrm{g})\end{array}$ & N.O & $\begin{array}{c}\text { Peso médio } \\
(\mathrm{g})\end{array}$ \\
\hline $1 . \div 9 \mathrm{e}-$ & 26 & 2.817 & 42 & 3.248 \\
\hline 1.50 a 1.54 & 65 & 3.116 & 68 & 3.353 \\
\hline 1.55 a 1.59 & 41 & 3.159 & 56 & 3.424 \\
\hline $1.60 \mathrm{e}+$ & 37 & 3.242 & 68 & 3.377 \\
\hline Todas as alturas & 169 & 3.107 & 234 & 3358 \\
\hline
\end{tabular}

O que talrez prejudique o critério para a indicação da restrição alimentar é que pode tratar-se, em certos casos, de uma recuperação nutricional que a mulher realiza ao mesmo tempo em que está grárida.

Assim, é válido supor que uma mulher com peso abaixo do normal tenha realmente necessidade de ganhar mais peso durante a gravidez pois, além do ganho gravídico, deve ocorrer uma engorda. 0 fato já foi descrito por Ciari Jr. ${ }^{5}$

A Tabela 2 relaciona o peso ao nascer. segundo a estatura, nos grupos "com" e "sem restrição alimentar".

$\mathrm{Na}$ Tabela 2 pode-se verificar que o peso médio do recém-nascido, em todos os 
CIARI Jr., C. et al. - Relação entre peso da criança ao nascer, altura materna, idade gestacional e restriçāo alimentar em gestantes normais. Rev. Saúde puibl., S. Paulo, 9:33-42, 1975.

sub-grupos de altura, era sempre menor no grupo "com restrição alimentar" A diferença entre os pesos ao nascer foi máxima para as mulheres de estatura menor que $1,50 \mathrm{~m}$.

Em média houve uma diferença. no peso ao nascer. de $251 \mathrm{~g}$ em favor dos filhos de mulheres que não tiveram restrição alimentar. fato.

A Figura 3 permite a visualização do

Tendo em rista estes resultados. dere-se reavaliar e reformular os esquemas rígidos de vigilância do aumento do peso durante a gravidez. Sabe-se que a desnutriçāo materna já deixa a sua marca. talvez indelével, no feto. Se além disso uma gestante subnutrida tiver uma restrição alimentar por vir engordando mais de um quilo por mês (e talvez ela esteja apenas recuperando seu estado nutricional), as consequiências para o feto poderão ser graves. Nunca é demais lembrar que este trabalho refere-se a gestantes normais, de hom nível sócio-econômico e, provavelmente. bem nutridas.

A restrição alimentar pode ocorrer de duas maneiras, excluída qualquer entidade mórbida. pois tratava-se de gestantes normais:

— iatrogênica;

— "automedicação" ou seja. a própria mulher diminui a ingestão de alimentos, seja por já ter sido assim orientada em gestação anterior, seja porque não engordar muito na gravidez já faça parte do consenso geral.

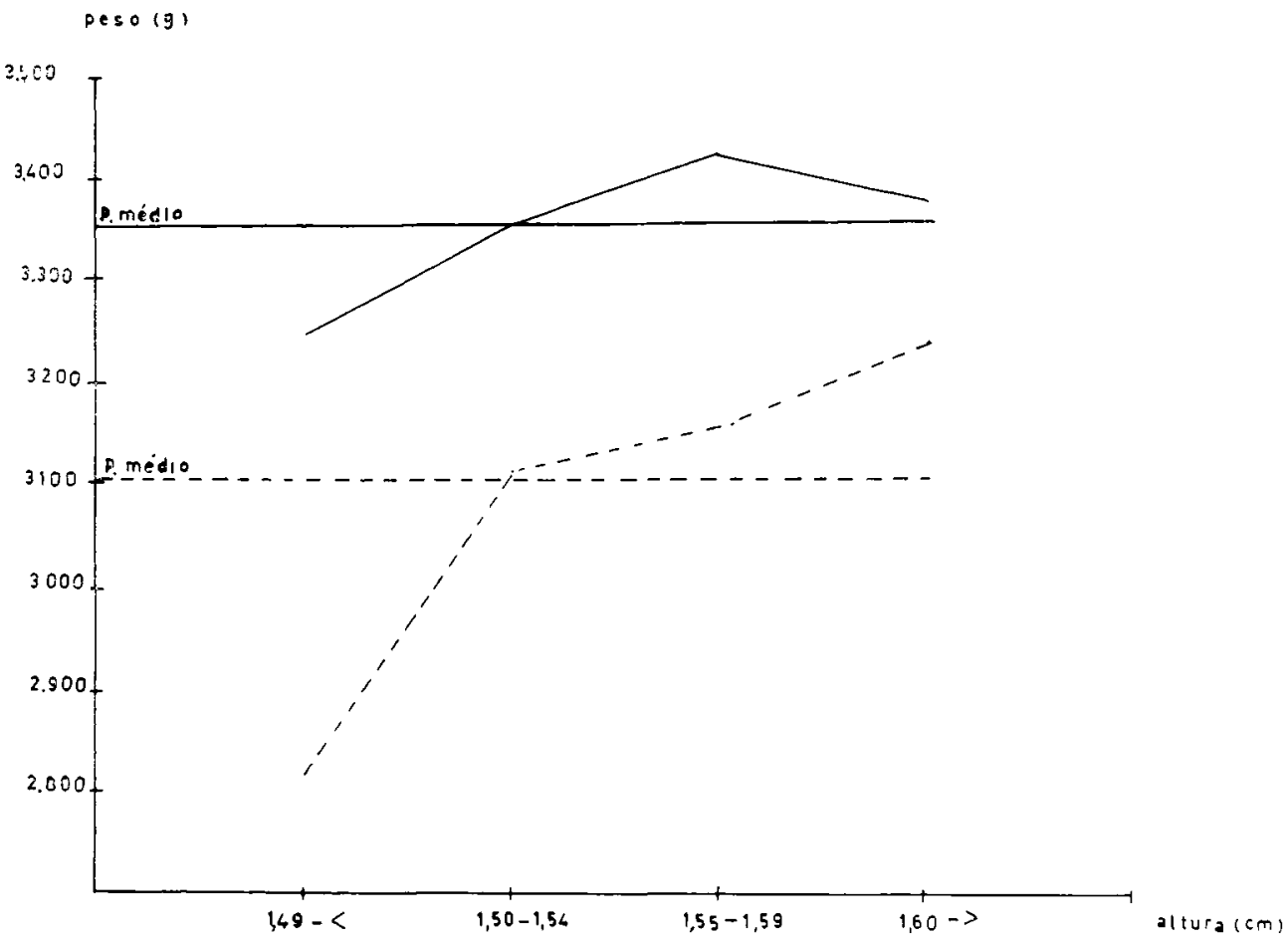

Fig. 3 - Pesc ao nascer segundo a altura da mãe e a ocorrência de restrição alimentar. 
CIARI Jr, C et al — Relação entre peso da criança ao nascer, altura materna, ldade gestacional e restrição alımentar em gestantes normais. Rei. Saúde publ, S Paulo, 9:33-42. 1975.

Qual seria, entāo, o ganho de peso ideal numa gestação normal?

O ganho de peso gravídico. isto é. determinado pelo peso do feto. placenta, líquido âmnico, aumento do peso do útero. mamas, tecido adiposo e aumento da água extracelular. tem sido calculado em torno de 9 quilos ${ }^{11}$.

No entanto. deve-se considerar que uma mulher magra pode estar, como já foi dito, ganhando peso não gravídico. num processo de recuperação nutricional. Para mulheres de estatura elevada. o próprio gawho gravídico pode ser maior. uma rez que ela possui maior rolume de água extracelular. tecido adiposo e, provavelmente. o feto será maior.

Num esquema rígido de controle do aumento de peso. é possível que as mulheres mais altas sofram mais intensamente de restrição alimentar. L'm indício de que isso possa estar ocorrendo é o fato de o peso médio ao nascer ser menor neste trahalho, em filhos de mulheres de 1.60 $\mathrm{m}$ e mais do que em mulheres de $1.55 \mathrm{~m}$ a 1.59, como pode ser visto na Tabela 1 .

Deve-se. contudo. lembrar que a manifestação inicial da toxemia gravídica pode ser um aumento rápido de peso. mesmo antes de haver edema clinicamente perceptível. ou hipertensão e proteinúria.

Assim. se este trabalho mostra um prejuízo inequívoco da restrição alimentar em gestantes normais sobre o peso ao nascer. não se pode prever o efeito de uma liberalização total da dieta da grávida sobre a incidência da toxemia e suas conseqüências.

Devido a essa dificuldade na conceituação do ganho de peso durante a gestação é que têm sido propostos e já têm sido realizados. em países desenrolvidos. estudos antropométricos em gestaçôes normais ${ }^{\&}$. Já tem sido elaboradas curras de ganho de peso durante a gravidez. Essas curvas não podem ser aplicadas em nosso meio, pois não consideram o tamanho (peso e aitura, da mulher e as gestantes incluídas nesse estudo têm. certamente. estatura inferior e ainda porque em países em desenvolvimento o problema da subnutrição da mulher, que modificaria o tipo de ganho de peso, é muito mais regra que exceção.

Decorre daí o interesse de conhecer a curva ponderal de gestantes normais em nosso meio. especialmente em Saúde Pública, pois existem métodos sofisticados para o diagnóstico do estado nutricional. métodos esses muito complicados e caros para serem aplicados em massa. T'ma curva. porém. que identificasse e discriminasse um ganho de peso maior devido à subnutrição. permitiria não só o diagnóstico nutricional da população de grávidas. como também o desenvolvimento de programas específicos de nutrição em Saúde Materna.

No caso especial do Centro de Saúde Geraldo de Paula Souza da Faculdade de Saúde Pública. os resultados deste estudo sugerem a conveniência de uma reeducação alimentar para as gestantes, no sentido de não restringirem a sua dieta, a não ser que houvesse uma prescrição médica nesse sentido. Essa prescrição médica não poderá. por outro lado, prender-se a esquemas rigorosos do tipo "engordar não mais de um quilo por mês": permitindo ganhos de peso maiores, sem deixar de lado o problema da toxemia.

L'ma outra abordagem do problema é a verificação da proporção de recém-nascidos de baixo peso em cada grupo de mulheres.

A proporção de recém-nascidos de baixo peso lexcluindo prematuros verdadeiros. pois só se trabalhou com gestações de 38 a 41 semanas), foi de $8.0 \%$. para o total de casos.

A Tahela 3 mostra as proporções de recém-nascidos de baixo peso segundo a altura da mulher e a ocorrência de restrição alimentar. 
CIARI Jr., C. et al. - Relação entre peso da criança ao nascer, altura materna, idade gestacional e restrição alimentar em gestantes normais. Rev. Saúde públ., S. Paulo, 9:33-42, 1975

TA B E L A 3

Proporção de recém-nascidos de baixo peso, em gestaçôes de 38 a 41 semanas, segundo a a altura da mãe e a restrição alimentar

\begin{tabular}{|c|c|c|c|c|c|c|}
\hline \multirow{3}{*}{ Altura (m) } & \multicolumn{3}{|c|}{ Com restrição alimentar } & \multicolumn{3}{|c|}{ Sem restrição alimentar } \\
\hline & \multirow[t]{2}{*}{$\begin{array}{c}\text { Total } \\
\text { de casos }\end{array}$} & \multicolumn{2}{|c|}{$\begin{array}{c}\text { Recém-nascidos de } \\
\text { baixo peso }\end{array}$} & \multirow[t]{2}{*}{$\begin{array}{l}\text { Total } \\
\text { de casos }\end{array}$} & \multicolumn{2}{|c|}{$\begin{array}{c}\text { Recém-nascidos de } \\
\text { baixo peso }\end{array}$} \\
\hline & & N.o & 'i & & No & $\%$ \\
\hline 1,49 e menos & 23 & 5 & 19.2 & 42 & 4 & 9,5 \\
\hline 1,50 a 1.54 & 65 & 7 & 10.8 & 68 & 4 & 5,9 \\
\hline 1.55 a 1.59 & 41 & 3 & 7,3 & 56 & 3 & 5,4 \\
\hline $1.60 \mathrm{e}+$ & 37 & 4 & 10.8 & 68 & 2 & 2,9 \\
\hline & 169 & 19 & 11.2 & 234 & 13 & 5.6 \\
\hline
\end{tabular}

Chamam a atenção as elevadas proporções de recém-nascidos de baixo peso no grupo "com restrição alimentar", com valores que chegam a $19,2 \%$ dos nascimentos, para mulheres de $1,49 \mathrm{~m}$ e menos.

Em média, 11,2\% dos recém-nascidos do grupo "com restrição alimentar" pesaram $2.500 \mathrm{~g}$ e menos ao nascer. Esse valor é muitíssimo elevado, levando-se em conta o fato de aqui estarem incluídos apenas recém-nascidos de termo (só foram estudadas neste trabalho gestações de 38 a 41 semanas).

Para o grupo "sem restrição alimentar" a proporção média de recém-nascidos de baixo peso foi de $5,6 \%$, valor considerado aceitável, apesar de ainda um pouco alto, principalmente considerando as condições sócio-econômicas do grupo estudado, que são boas. Essa proporção um pouco elevada deve-se à ocorrência, em gestantes de $1,49 \mathrm{~m}$ e menos, de quase $10 \%$ de recém-nascidos de baixo peso.

À guisa de comparação entre os dois grupos, pode-se calcular o risco que as mulheres do grupo "com restrição alimentar" apresentam de ter um filho de baixo peso, quando se considera o risco do grupo "sem restrição alimentar" com valor um. Assim, as mulheres de $1,49 \mathrm{~m}$ e menos têm risco de 2,02 , as de $1,50 \mathrm{~m}$ a $1,54 \mathrm{~m}$ de 1,83 , as de $1.55 \mathrm{~m}$ a $1,59 \mathrm{~m}$ de 1,35 e para as de $1,60 \mathrm{~m}$ e mais o risco é de 3,72 !

Pode-se também calcular o excesso de recém-nascidos de baixo peso decorrentes da restrição alimentar. Para tanto, basta aplicar ao grupo "com restrição alimentar" as proporções verificadas no outro grupo.

Assim, pode-se dizer que, dos 19 nascimentos de baixo peso do grupo "com restrição alimentar", há um excesso de 10 em relação ao outro grupo. Esses 10 nascimentos devem-se, então, à restrição alimentar.

Em outros termos, um terço de todos os recém-nascidos de baixo peso, incluidos neste trabalho, poderiam ter nascido com melhor peso e, assim, em melhores condições de suportar os agravos futuros, se suas mães não se tivessem submetido a dietas restritivas durante a gravidez. 
CIARI Jr., C. et al. - Relação entre peso da criança ao nascer, altura materna, idade gestacional e restriçáo alimentar em gestantes normais. Rev. Saúde públ., S. Paulo, 9:33-42, 1975.

\section{CONCLUSOES}

1) O peso do recém-nascido acompanha - aumento da altura materna e da idade gestacional, confirmando outros trabalhos.

2) A ocorrência de gestações de 38 e 39 semanas em mulheres de estatura inferior a $1.50 \mathrm{~m}$ pode ser considerada um fator de risco fetal.

3) Em filhos de mulheres normais em que houve restrição alimentar durante a gravidez houve uma diminuição de 251 g no peso médio ao nascer.

4) A incidência de recém-nascidos de baixo peso texcluindo prematuros verdadeiros) é dupla em mulheres "com restrição alimentar", quando comparadas com mulheres "sem restrição alimentar"

5) O maior prejuízo no peso ao nascer que sofrem os filhos de mulheres de maior estatura pode estar relacionado a maiores restriçôes alimentares impostas a suas mães durante a gestação.

6) L'm terço de todos os recém-nascidos de baixo peso, pequenos para a idade gestacional, ocorridos nos nascimentos aqui considerados, deveu-se provavelmente à restrição alimentar.

CIARI Jr.. C. et al. - [Relation between weight at birth, maternal height, gestational age and feeding restrictions in nomal pregnant women.] Rev. Saúde púbi., S. Paulo, 9:33-42, 1975.

Summary: The influence of maternal height, gestacional age and feeding restrictions in normal pregnant women on the weight at birth of offspring was studied. The results showed that the weight at birth rises along with maternal height and gestational age. Feeding restrictions caused a decrease of 251 grammes in the average newborn weight and was responsible for a third of all burths of underweight children. The authors consider that, in women less than $1.50 \mathrm{~m}$ tall, pregnancies of 38 and 39 weeks may increase fetal risk. The prescription of restrictive diets to normal pregnant women should not be founded solely on rigid weight-gaining schemes due to damage that may be carsed to the newborns' weight.

UNiterms: Weight at birth.- Gestational age. Maternal height. Feeding of the pregnant woman.

\section{REFERENCIAIS BIBLIOGRÁFICAS}

1. ALvarenga, A.T. de et al. - Indice de status sócio-económico da familia da mulher grávida que frequenta o Centro de Saúde Geraldo de Paula Souza da Faculdade de Saúde Pública da Nniversidade de São Paulo. Rer. Saúde púb7. S. Paulo, 7:35̃67, 1973

2. BERGNER, L \& SLSSER, MI W. - LOW birth weight and prenatal nutrition: an interpretative review. Pediatrics, 46:946-66, 1970 .

3. BUTLER, N.R. \& BONHAM, D.G. Perinatal mortality: the fust report of the 1958 British Perinatal Mortality Survey. Edinburgh, Iuvingstone, 1963. 
CIARI Jr., C. et al. - Relação entre peso da criança ao nascer, altura materna, idade gestacional e restrição alimentar em gestantes normais. Rev. Saúde públ., S. Paulo, 9:33-42, 1975.

4. CHASE, H.C. - International comparisons of perinatal and infant mortality. Vital Hlth Stat. Series 3, Analyt. Stud. (6), Mar. 1967.

5. CIARI Jr., C. - Curva ponderal de gestantes normais. A Folha Médica, Rio de Janeiro, 68:141-6, 1974.

6. JELLIFFE, D.B. - Evaluación del estado de nutrition de la comunidad con especial referencia a las encuestas en las regrones en desarrollo). Genebra, Organización Mundial de la Salud. 1968. [Serie de Monografias, 53 .

7. LAURENTI, R. \& SIQUEIRA, A.A.F. de - O problema da mortalidade neonatal em São Paulo, Brasil. Rev. saude publ., S. Paulo, 6:45-55, 1972.

8. MATERNAL Nutritional assessment Amer. J. publ Hith, 63(Suppl.):5763. Nov. 1973.

9. MILANESI, M.I. \& LAURENTI, R. Mortalidade infantil no municipio de São Paulo: análise do seu comportamento nos últimos 15 anos. Rev. Saúde públ., S. Paulo, 1:44-50, 1971.

10. NEME, B. - Assistência médico-sanitária e médico-hospitalar à mulher - aspectos da situação atual no Estado de São Paulo: editorial. Matern. e Inf., 32:v-xix, out.-dez. 1973.

11. ORGANIZACIÓN MUNDIAL DE LA SA. LUD. Comite de Expertos de la OMs sobre la Nutricion Durante el Emba. razo y la Lactancia. Ginebra, 196.1 Informe, Ginebra, 1960 . [Ser. Inf. técn. 302].

12. PUFFER, R.R. \& SERRANO, C.V. Patterns of mortality in childhood. Washington, D.C., Pan American Health Organization, 1973. [Scientiflc Publication, 262].

13. SIQUEIRA, A.A.F. de - Mortalidade neo-natal e prematuridade. São Pau10, 1974. [Monografia de mestrado - Faculdade de Saúde Pública [SP].

14. THOMSON, A.M. et al. - The assessment of fetal growth. J. Obstet. Gynec Brit. Culth., 75:903-16, 1968.

15. WINICK, M. - Current status of malnutrition in the United States. Amer. J. trop. Med. Hyg., 23:752-5, 1974.

Recebido para publicação em 13-12-74 Aprovado para publicasão em 13-01-75 